\title{
Comparison of emergency cholecystectomy and delayed cholecystectomy after percutaneous transhepatic gallbladder drainage in patients with acute cholecystitis: a systematic review and meta-analysis
}

\author{
Shao-Zhuo Huang ${ }^{1} \cdot$ Hao-Qi Chen ${ }^{2} \cdot$ Wei-Xin Liao ${ }^{3} \cdot$ Wen-Ying Zhou ${ }^{4} \cdot$ Jie-Huan Chen ${ }^{5} \cdot$ Wen-Chao Li ${ }^{1} \cdot$ Hui Zhou $^{1}$. \\ Bo Liu ${ }^{1} \cdot$ Kun-Peng Hu${ }^{1}$
}

Received: 24 April 2020 / Accepted: 28 September 2020 / Published online: 13 October 2020

(C) The Author(s) 2020

\begin{abstract}
Laparoscopic cholecystectomy and percutaneous transhepatic gallbladder drainage (PTGBD) are common treatments for patients with acute cholecystitis. However, the safety and efficacy of emergency laparoscopic cholecystectomy (ELC) and delayed laparoscopic cholecystectomy (DLC) after PTGBD in patients with acute cholecystitis remain unclear. The PubMed, EMBASE, and Cochrane Library databases were searched through October 2019. The quality of the included nonrandomized studies was assessed using the Methodological Index for Nonrandomized Studies (MINORS). The meta-analysis was performed using STATA version 14.2. A random-effects model was used to calculate the outcomes. A total of fifteen studies involving 1780 patients with acute cholecystitis were included in the meta-analysis. DLC after PTGBD was associated with a shorter operative time (SMD $-0.51 ; 95 \% \mathrm{CI}-0.89$ to $-0.13 ; P=0.008$ ), a lower conversion rate (RR $0.43 ; 95 \% \mathrm{CI} 0.26$ to $0.69 ; P=0.001$ ), less intraoperative blood loss (SMD $-0.59 ; 95 \% \mathrm{CI}-0.96$ to $-0.22 ; P=0.002$ ) and longer time of total hospital stay compared to ELC (SMD 0.91; 95\% CI 0.57-1.24; $P<0.001$ ). There was no difference in the postoperative complications (RR 0.68 ; 95\% CI 0.48-0.97; $P=0.035$ ), biliary leakage (RR $0.65 ; 95 \%$ CI $0.34-1.22 ; P=0.175$ ) or mortality (RR 1.04; 95\% CI 0.39-2.80; $P=0.933$ ). Compared to ELC, DLC after PTGBD had the advantages of a shorter operative time, a lower conversion rate and less intraoperative blood loss.
\end{abstract}

Keywords Cholecystectomy $\cdot$ PTGBD $\cdot$ Acute cholecystitis $\cdot$ Meta-analysis

Shao-Zhuo Huang, Hao-Qi Chen and Wei-Xin Liao contributed equally to this work.

\section{Bo Liu}

jakeliubo@qq.com

$\triangle$ Kun-Peng $\mathrm{Hu}$

hkpdhy918@126.com

1 Department of General Surgery, The Third Affiliated Hospital, Sun Yat-sen University, Guangzhou, China

2 Department of Hepatic Surgery, The Third Affiliated Hospital, Sun Yat-sen University, Liver Transplantation, Guangzhou, China

3 Department of Infectious Diseases, The Third Affiliated Hospital, Sun Yat-sen University, Guangzhou, China

4 Department of Laboratory Medicine, The Third Affiliated Hospital of Sun Yat-sen University, Guangzhou, China

5 Department of Ultrasound, Binhaiwan Central Hospital of Dongguan, Dongguan, China

\section{Introduction}

Acute cholecystitis (AC), an inflammatory condition of the gallbladder, is also a common disease that involves hospitalization and surgical treatment [1]. Patients with AC may present with a wide spectrum of inflammation, which may progress to empyema, perforation, and abscess formation, with an overall mortality rate of approximately $0.6 \%$ [2-4]. Since the first cholecystectomy was performed with the use of an operative laparoscope 30 years ago [5], laparoscopic cholecystectomy (LC) is currently recognized as a standard treatment for AC. In most AC patients, laparoscopic cholecystectomy can rapidly attenuate inflammatory symptoms and signs. Nevertheless, LC may precipitate certain complications, such as biliary leakage, bile duct injury and intraabdominal abscess $[6,7]$, especially in elderly AC patients who undergo emergency laparoscopic cholecystectomy, 
which may cause high morbidity and mortality rates [8]. Several studies have also documented that LC is associated with a high rate of conversion to open cholecystectomy and a long length of hospital stay $[9,10]$.

Percutaneous transhepatic gallbladder drainage (PTGBD), which was first applied by Radder in 1980 [11], is a minimally invasive operation performed to relieve gallbladder tension through external drainage under ultrasound or CT guidance [3]. According to the 2018 Tokyo guidelines for drainage management of AC, PTGBD can alleviate inflammation caused by edema of the gallbladder wall and pericholecystic adhesions, and it has the advantage of a lower risk of adverse events compared with cholecystectomy, which is an alternative to surgical treatment in highrisk AC patients $[6,12,13]$. Previous studies have reported that LC performed after PTGBD has several advantages, such as early symptom remission, surgery facilitation and patient stabilization [14-16]. However, PTGBD may also cause complications related to the procedure, such as bile leakage and pain at the puncture site $[16,17]$. For severe AC patients, studies have shown that PTGBD is related to a high mortality rate and prolonged hospital stay [18]. In addition, biliary obstruction and cholestasis caused by gallstones are the major causes of acute cholecystitis, which is difficult to treat with PTGBD [19]. Besides, PTGBD may lead to complications associated with the drainage tube, such as obstruction of the drainage by stones and debris, pierced gallbladder and slipping off drainage tube [17].

The effects of emergency laparoscopic cholecystectomy (ELC) and delayed laparoscopic cholecystectomy (DLC) after PTGBD in AC patients remain unclear. Therefore, we conducted this meta-analysis to better understand and compare the safety and efficacy of ELC and PTGBD followed by DLC in AC patients in terms of the operative time, rate of conversion to open surgery, length of hospital stay, intraoperative blood loss, postoperative complications, biliary leakage and mortality.

\section{Materials and methods}

\section{Data source}

This study was carried out according to the Preferred Reporting Items for Systematic Reviews and Meta-Analyses 2009 guidelines [20]. Conducted by two authors (H.S. and C.H.), the search was performed using PubMed (1980 to October 2019), EMBASE (1988 to October 2019), and the Cochrane Central Register of Controlled Trials. The following medical subject terms were used in the search: ("cholecystectomy" OR "cholecystectomies") AND ("drainage") AND ("cholecystitis" OR "gallbladder Inflammation" OR "inflammation, gallbladder" OR "empyema, gallbladder" OR "gallbladder empyema" OR "empyema, gall bladder" OR "gall bladder empyema"). Neither IRB approval nor written consent was required for this study.

\section{Study selection}

Duplicates were removed. Titles and abstracts were independently screened by the reviewers (H.S. and C.H.) to assess the relevance of the publications. Subsequently, full-text articles were retrieved and checked. The remaining articles were surveyed by cross-referenced searches to detect studies that might have been overlooked. All studies concerned patients treated with emergency cholecystectomy and delayed cholecystectomy after percutaneous transhepatic gallbladder drainage for acute cholecystitis. The criteria for the diagnosis of acute cholecystitis had to be defined in the article, and acute cholecystitis had to be proven either by ultrasound or histologically. No language or publication types were restricted. Studies only aimed at severe cases or special population were excluded. Studies lacking necessary data or control groups were excluded. In studies with multiple publications from the same population, only the most recent one was included. Letters, posters, conference abstracts, expert opinions, review articles, case reports, animal experiments, and in vitro studies were also excluded. The selection process of the studies is shown in Fig. 1.

\section{Data extraction}

Data were extracted independently from each study by two investigators (H.S. and C.H.). The following items recorded for each study were extracted: first author, year of publication, age, country, number of controls and cases, study period, and time between PTGBD and LC. However, some studies expressed data with medians and ranges. We changed these data means with standard deviations [21]. Quantitative statistics were reported as the mean \pm SD.

\section{Quality assessment}

All of the studies were retrospective. The data quality of nonrandomized studies was assessed using the Methodological Index for Nonrandomized Studies (MINORS) (Table 1) [22]. MINORS, an index designed to assess the methodological quality of nonrandomized surgical studies, was developed by a group of surgeons because of the problems faced by clinicians as to the lack of randomized surgical trials and the large number of observational studies in surgery. By considering 12 items ( 8 for noncomparative and 4 for comparative studies), the total score was calculated by summing the values attributed as follows: 0 (not reported), 1 (reported but inadequate), 
Fig. 1 PRISMA flow diagram of literature screening

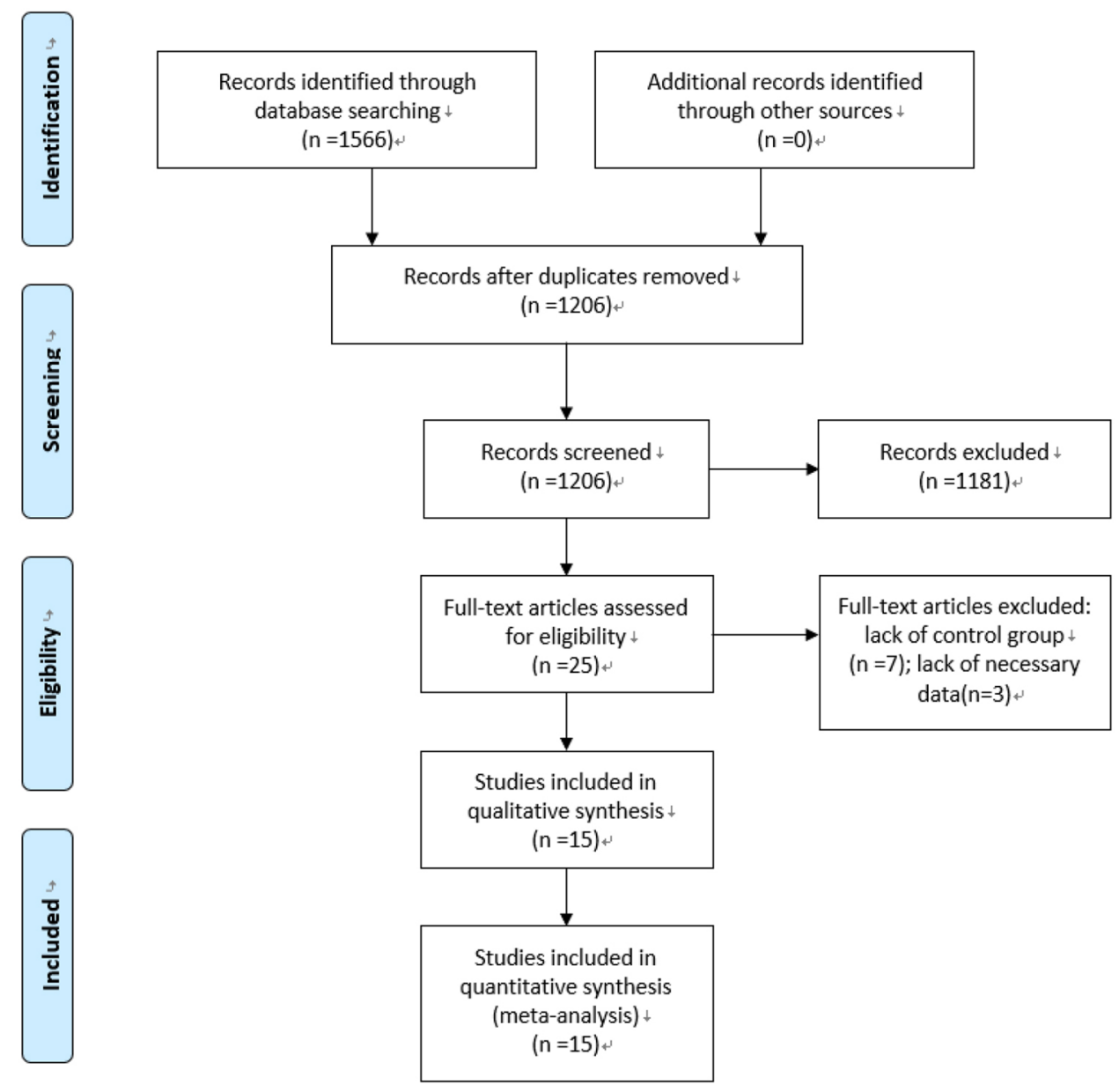

and 2 (reported and adequate). The global ideal score for noncomparative studies was 16 and for comparative studies was 24 .

\section{Statistical analysis}

Data from the eligible studies were extracted independently. Statistics Analysis (STATA version 14.2) (Stata Corporation; College Station, TX, USA) was used to perform the data analysis. Differences between groups were expressed as RRs with $95 \%$ CIs. The random-effect models were used to calculate the outcomes [23]. All statistical analyses used in this study were two-sided, and $P<0.05$ was regarded as statistically significant.

Cochran's $Q$ test and $I^{2}$ statistic were used to evaluate the heterogeneity across the studies. Cochran's $Q<0.10$ or $I^{2}>50 \%$ was regarded as significant heterogeneity across studies [24, 25]. To evaluate the extent of publication bias, Egger's test and Begg's test were used [26, 27]. Subgroup analysis was used to decrease the heterogeneity among studies.

\section{Results}

\section{Literature retrieval and study selection}

A total of 1566 articles were retrieved from the electronic databases (PubMed [ $n=732]$, EMBASE [ $n=817]$, and Cochrane $[n=17])$. Cross-referenced searches did not find new articles. After removing duplicates $(n=360)$, the titles and abstracts of the remaining articles were examined. A total of 1181 articles were excluded because of irrelevancy. Subsequently, the remaining 25 articles were retrieved for detailed assessments based on the full texts. Among these 25 articles, 10 were excluded because of a lack of a control group $(n=7)$ and necessary data $(n=3)$. Finally, 15 articles were included in this meta-analysis [3, 4, 6, 10, 15-17, 28-35]. 


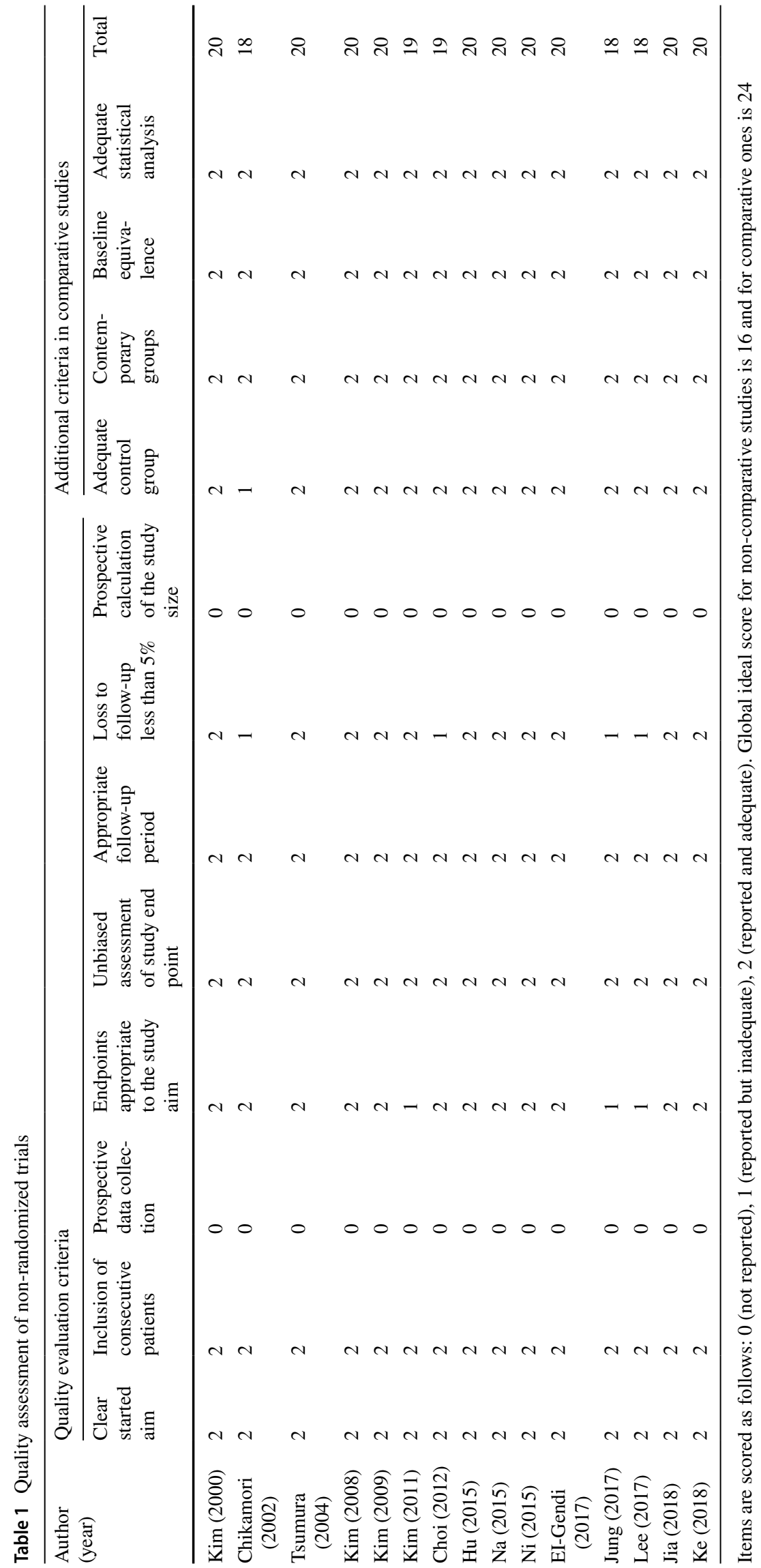


Table 2 Characteristics of the included studies

\begin{tabular}{|c|c|c|c|c|c|c|}
\hline Author & Year & $\begin{array}{l}\text { Mean } \pm \text { SD } \\
\text { Age (years) }\end{array}$ & Country & Control/cases & Study period & $\begin{array}{l}\text { Time between } \\
\text { PTGBD and LC } \\
\text { (days) }\end{array}$ \\
\hline Kim & 2000 & $\begin{array}{l}\text { ELC: } 51 \pm 13 \\
\text { PTGBD+DLC: } 53 \pm 12.5\end{array}$ & Korea & $45 / 27$ & 1994-1999 & $<7$ \\
\hline Chikamori & 2002 & $\begin{array}{l}\text { ELC: } 67 \pm 13 \\
\text { PTGBD+DLC: } 65 \pm 10\end{array}$ & Japan & $9 / 31$ & 1998-2002 & $<7$ \\
\hline Tsumura & 2004 & $\begin{array}{l}\text { ELC: } 55.4 \pm 16.7 \\
\text { PTGBD+DLC: } 64.5 \pm 13.6\end{array}$ & Japan & $73 / 60$ & 1998-2003 & $>7$ \\
\hline Kim & 2008 & $\begin{array}{l}\text { ELC: } 60.5 \pm 13.4 \\
\text { PTGBD+DLC: } 66.8 \pm 11.7\end{array}$ & Korea & $62 / 37$ & 2003-2006 & $>7$ \\
\hline Kim(1) & 2009 & $\begin{array}{l}\text { ELC: } 55.5 \pm 13.3 \\
\text { PTGBD+DLC: } 57.7 \pm 11.9\end{array}$ & Korea & $60 / 35$ & 2002-2007 & $<7$ \\
\hline Kim(2* & 2009 & $\begin{array}{l}\text { ELC: } 55.5 \pm 13.3 \\
\text { PTGBD+DLC: } 61.0 \pm 12.1\end{array}$ & Korea & $60 / 38$ & 2002-2007 & $>7$ \\
\hline Kim & 2011 & $\begin{array}{l}\text { ELC: } 55.5 \pm 13.3 \\
\text { PTGBD+DLC: } 66.4 \pm 15.3\end{array}$ & Korea & $147 / 97$ & 2006-2009 & $<7$ \\
\hline Choi & 2012 & $\begin{array}{l}\text { ELC: } 60.4 \pm 13.0 \\
\text { PTGBD+DLC: } 72.5 \pm 12.6\end{array}$ & Korea & $63 / 60$ & 2007-2011 & $<7$ \\
\hline $\mathrm{Hu}$ & 2015 & $\begin{array}{l}\text { ELC: } 71.5 \pm 11.5 \\
\text { PTGBD+DLC: } 72.5 \pm 12.6\end{array}$ & China & $35 / 35$ & 2010-2014 & $>7$ \\
\hline $\mathrm{Na}$ & 2015 & $\begin{array}{l}\text { ELC: } 72.55 \pm 7.00 \\
\text { PTGBD + DLC: } 72.95 \pm 7.49\end{array}$ & Korea & $77 / 39$ & 2009-2013 & $<7$ \\
\hline $\mathrm{Ni}$ & 2015 & $\begin{array}{l}\text { ELC: } 59.0 \pm 12.9 \\
\text { PTGBD+DLC: } 65.6 \pm 13.6\end{array}$ & China & $33 / 26$ & 2005-2012 & $>7$ \\
\hline EI-Gendi & 2017 & $\begin{array}{l}\text { ELC: } 50.19 \pm 12.01 \\
\text { PTGBD+DLC: } 49.65 \pm 11.63\end{array}$ & Egypt & $75 / 75$ & 2014-2016 & $>7$ \\
\hline Jung & 2017 & $\begin{array}{l}\text { ELC: } 56.3 \pm 15.5 \\
\text { PTGBD+DLC: } 64.9 \pm 14.9\end{array}$ & Korea & $166 / 128$ & 2010-2014 & $>7$ \\
\hline Lee & 2017 & $\begin{array}{l}\text { ELC: } 61.6 \pm 15.6 \\
\text { PTGBD + DLC: } 69.0 \pm 11.5\end{array}$ & Korea & $41 / 44$ & 2013-2016 & $>7$ \\
\hline Jia & 2018 & $\begin{array}{l}\text { ELC: } 65.28 \pm 16.71 \\
\text { PTGBD + DLC: } 62.11 \pm 13.1\end{array}$ & China & $48 / 38$ & 2013-2015 & $<7$ \\
\hline $\mathrm{Ke}$ & 2018 & $\begin{array}{l}\text { ELC: } 62 \pm 16 \\
\text { PTGBD+DLC: } 67 \pm 14\end{array}$ & China & $47 / 49$ & 2013-2017 & $>7$ \\
\hline
\end{tabular}

$S D$ standard deviation, $P T G B D$ percutaneous transhepatic gallbladder drainage, $L C$ laparoscopic cholecystectomy, $E L C$ emergency laparoscopic cholecystectomy, DLC delayed laparoscopic cholecystectomy

*Kim(1) and Kim(2) came from the same study that split into two groups according to the time between PTGBD and LC

\section{Study characteristics and quality}

The characteristics of the 15 included studies are shown in Table 2. Of the 15 included studies, 8 were conducted in Korea, 4 in China, and 2 in Japan, and the remaining study was conducted in Egypt. In addition, patients in six studies underwent LC after PTGBD within 7 days. Patients in eight studies underwent LC after PTGBD after 7 days. Specifically, one of the studies included both of these groups, so we split it into two groups: Kim(1) and Kim(2)

Based on the quality assessment of MINORS, ten studies [3, 4, 10, 17, 28-33] scored 20 points, two studies [15, $34]$ scored 19 points, and three studies $[6,16,35]$ scored 18 points. All studies had a nonrandomized design.

\section{Operative time of LC}

All 15 studies [3, 4, 6, 10, 15-17, 28-35] reported the operative time of LC. All of these studies were analyzed by the mean with standard deviation. As shown in Fig. 2, 799 patients underwent LC after PTGBD, and 981 underwent ELC. According to the random-effects model, the pooled operative time of LC in the PTGBD group was shorter than that in the ELC group (SMD - $0.51 ; 95 \%$ CI -0.89 to $-0.13 ; P=0.008)$. There was a significant difference in heterogeneity among the studies $(Q=218.94$; $P$ for heterogeneity $\left.<0.001 ; I^{2}=93.1 \%\right)$. 
Fig. 2 Forest plot of operative time of LC after PTGBD in patient with acute cholecystitis
Fig. 3 Forest plot of conversion rate of LC after PTGBD in

patient with acute cholecystitis

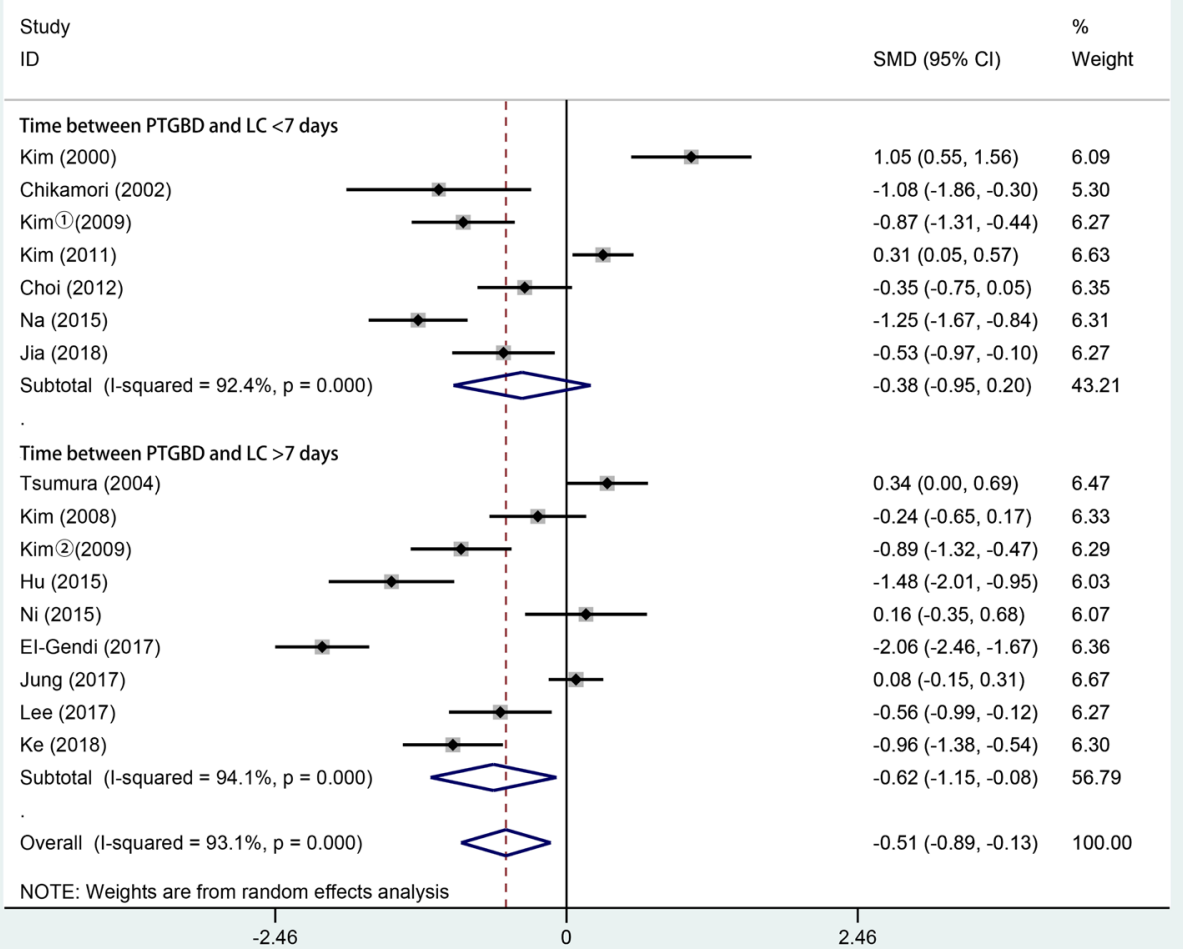

\section{Study}

ID
$\%$

Weight

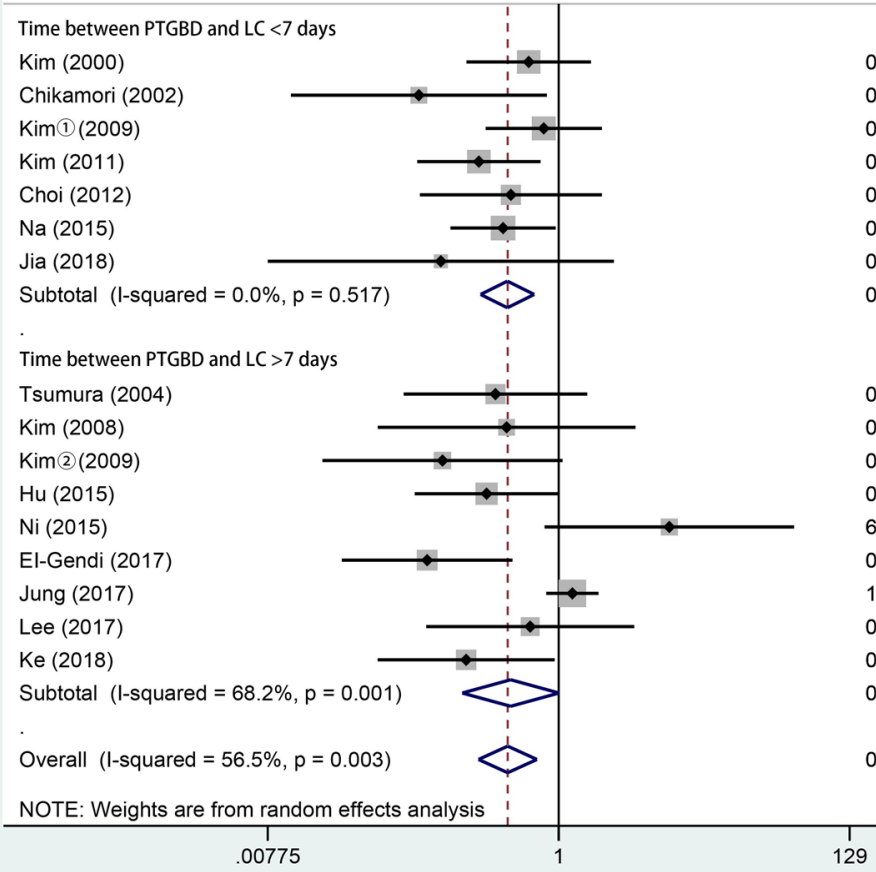

$0.61(0.21,1.71) \quad 8.24$

$0.10(0.01,0.82) \quad 3.73$

$0.78(0.29,2.06) \quad 8.66$

$0.26(0.09,0.74) \quad 8.30$

$0.45(0.10,2.06) \quad 5.78$

$0.39(0.16,0.95) \quad 9.23$

$0.14(0.01,2.52) \quad 2.34$

$0.42(0.27,0.66) \quad 46.29$

$0.35(0.07,1.61) \quad 5.72$

$0.42(0.05,3.61) \quad 3.69$

$0.14(0.02,1.07) \quad 4.08$

$0.30(0.09,1.00) \quad 7.32$

$6.35(0.79,51.03) \quad 3.87$

$0.11(0.03,0.46) \quad 6.20$

$1.26(0.81,1.94) \quad 11.93$

$0.62(0.11,3.53) \quad 4.93$

$0.21(0.05,0.94) \quad 5.96$

$0.45(0.20,1.01) \quad 53.71$

$0.43(0.26,0.69) \quad 100.00$ 


\section{Conversion rate}

All 15 studies [3, 4, 6, 10, 15-17, 28-35] reported the conversion rate from LC to OC. As shown in Fig. 3, 799 patients underwent LC after PTGBD, and 981 underwent ELC. According to the random-effects model, the pooled conversion rate of LC after PTGBD was favorable in the ELC group (RR 0.43; 95\% CI 0.26-0.69; $P=0.001$ ). There was a significant difference in heterogeneity among the studies $\left(Q=34.49 ; P\right.$ for heterogeneity $\left.=0.003 ; I^{2}=56.5 \%\right)$.

\section{Total hospital stay}

Eleven studies [3, 4, 6, 10,15-17, 29-35] reported the total hospital stay. All of these studies were analyzed by the mean with standard deviation. As shown in Fig. 4, 602 patients underwent LC after PTGBD, and 813 underwent ELC. According to the random-effects model, the total hospital stay of LC after PTGBD group was longer than the ELC group (SMD 0.91; 95\% CI 0.57-1.24; $P<0.001$ ). There was a significant difference in heterogeneity among the studies $\left(Q=91.22 ; P\right.$ for heterogeneity $\left.<0.001 ; I^{2}=87.9\right)$.

\section{Intraoperative blood loss}

Eight studies [3, 4, 10, 15, 17, 29-31] reported intraoperative blood loss. As shown in Fig. 5, 362 patients underwent
LC after PTGBD, and 451 underwent ELC. According to the random-effects model, the intraoperative blood loss of LC in the PTGBD group was less than that in the ELC group (SMD $-0.59 ; 95 \% \mathrm{CI}-0.96$ to $-0.22 ; P=0.002$ ). There was a significant difference in heterogeneity among the studies $\left(Q=45.50 ; P\right.$ for heterogeneity $\left.<0.001 ; I^{2}=84.6 \%\right)$.

\section{Postoperative complications}

All studies [3, 4, 6, 10, 15-17, 28-35] reported postoperative complications, such as postoperative bleeding and persistent inflammation. As shown in Fig. 6, 799 patients underwent LC after PTGBD, and 981 underwent ELC. According to the random-effects model, the postoperative complications of LC in the PTGBD group were less severe than those in the ELC group (RR $0.68 ; 95 \%$ CI $0.48-0.97 ; P=0.035$ ). There was no significant difference in heterogeneity among the studies $\left(Q=24.88 ; P\right.$ for heterogeneity $\left.=0.052 ; I^{2}=39.7 \%\right)$.

\section{Biliary leakage}

Thirteen studies $[3,4,6,10,15-17,28-33]$ reported data on biliary leakage. As shown in Fig. 7, 658 patients underwent LC after PTGBD, and 793 underwent ELC. According to the random-effects model, there were no significant differences in biliary leakage between the two groups (RR 0.65; $95 \%$ CI 0.34 to $1.22 ; P=0.175)$. There was no significant
Fig. 4 Forest plot about time of total hospital stay of LC after PTGBD in patient with acute cholecystitis

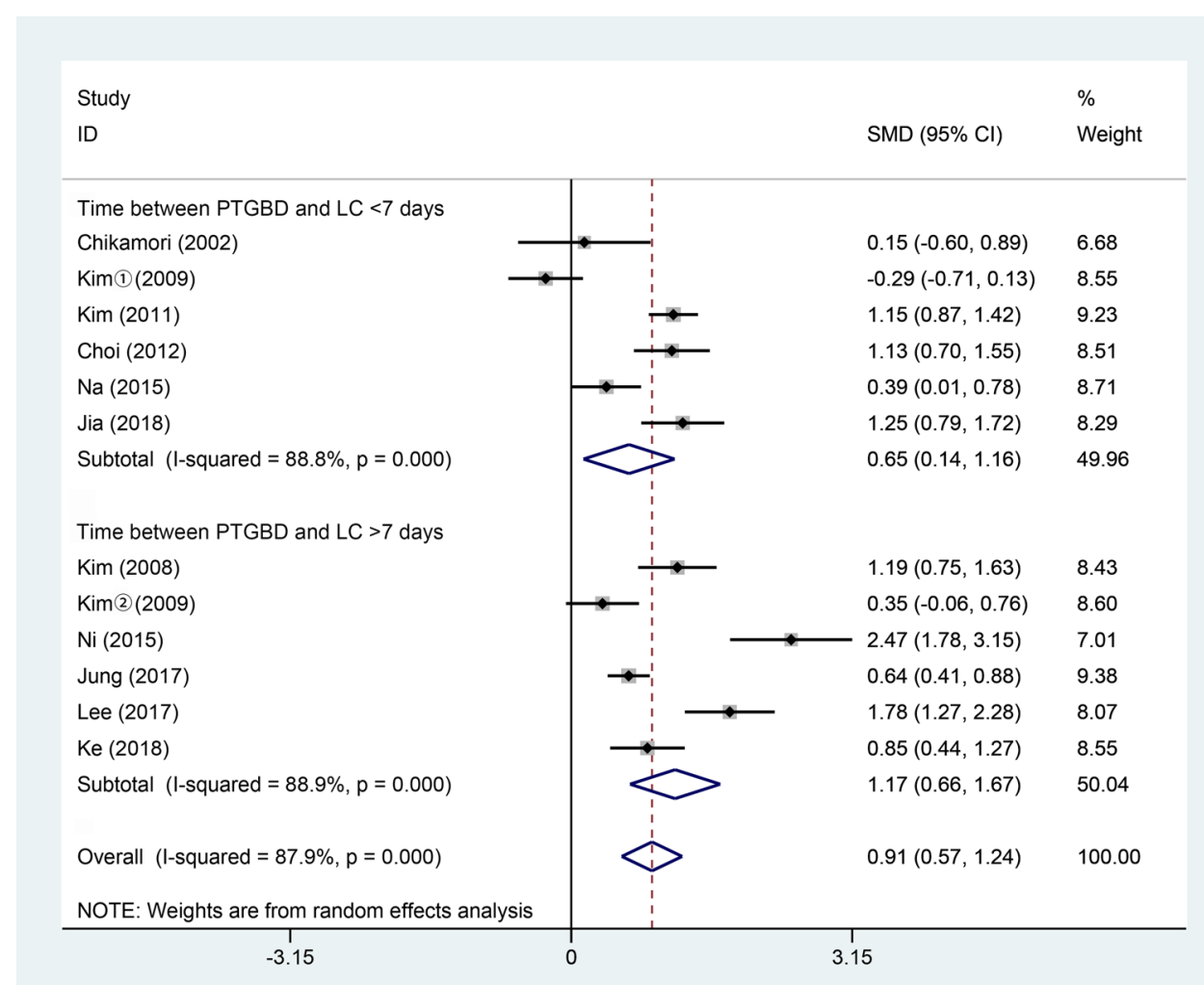


Fig. 5 Forest plot of intraoperative blood loss of LC after PTGBD in patient with acute cholecystitis
Study

SMD $(95 \% \mathrm{Cl}) \quad$ Weight

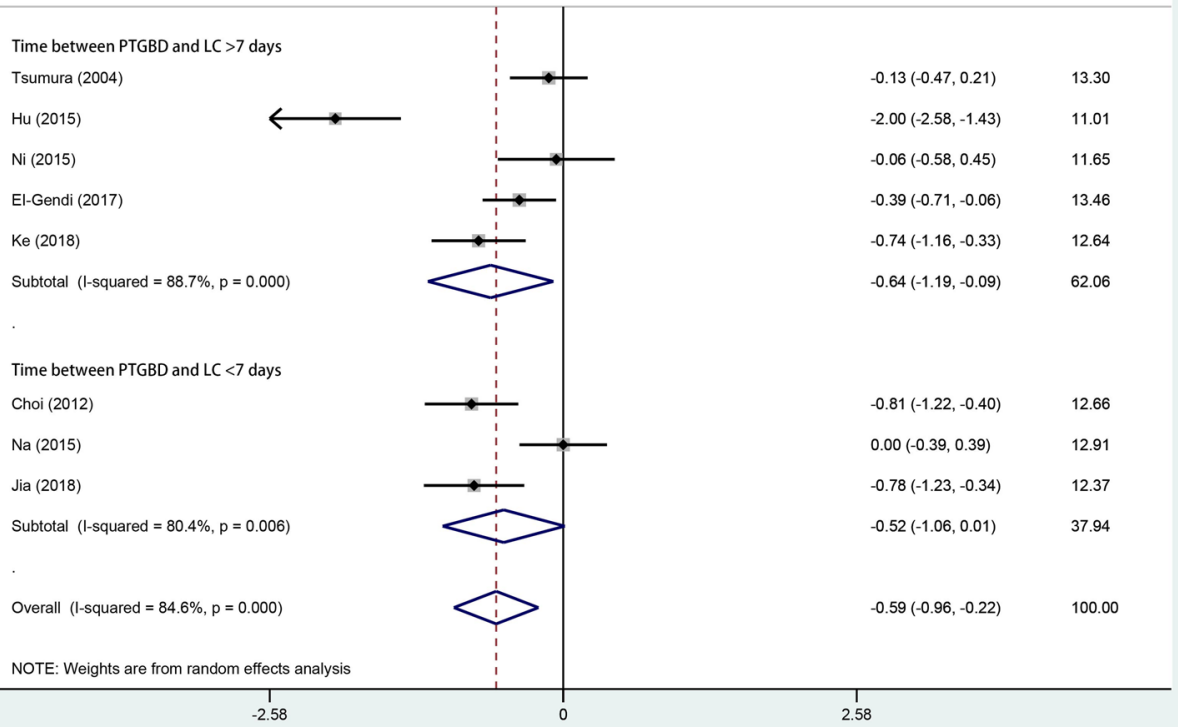

Fig. 6 Forest plot of postoperative complications of LC after PTGBD in patient with acute cholecystitis

Study

ID

Time between PTGBD and LC $<7$ days

Kim (2000)

Chikamori (2002)

Kim(1) (2009)

Kim (2011)

Choi (2012)

$\mathrm{Na}$ (2015)

Jia (2018)

Subtotal $(\mathrm{I}$-squared $=16.7 \%, p=0.302)$

Time between PTGBD and LC $>7$ days

Tsumura (2004)

$\operatorname{Kim}(2008)$

Kim(2) (2009)

$\mathrm{Hu}$ (2015)

$\mathrm{Ni}$ (2015)

El-Gendi (2017)

Jung (2017)

Lee (2017)

Ke (2018)

Subtotal $(\mathrm{I}$-squared $=54.4 \%, \mathrm{p}=0.025$ )

Overall (I-squared $=39.7 \%, p=0.052$ )

NOTE: Weights are from random effects analysis

$$
.00326
$$

RR $(95 \% \mathrm{Cl}) \quad$ Weight

$2.22(0.54,9.18) \quad 4.80$

$0.06(0.00,1.20) \quad 1.36$

$0.43(0.13,1.42) \quad 6.16$

$0.57(0.15,2.09) \quad 5.45$

$0.74(0.33,1.64) \quad 9.90$

$0.99(0.51,1.90) \quad 11.94$

$0.42(0.09,1.97) \quad 4.21$

$0.73(0.46,1.17) \quad 43.82$

$1.06(0.41,2.77) \quad 8.21$

$0.72(0.20,2.61) \quad 5.53$

$0.26(0.06,1.11) \quad 4.69$

$0.25(0.06,1.09) \quad 4.51$

$1.26(0.03,61.42) \quad 0.81$

$0.10(0.02,0.41) \quad 4.80$

$5.19(0.59,45.85) \quad 2.36$

$0.80(0.29,2.18) \quad 7.73$

$0.96(0.71,1.29) \quad 17.56$

$0.63(0.36,1.11) \quad 56.18$

$0.68(0.48,0.97) \quad 100.00$ 
Fig. 7 Forest plot of biliary leak of LC after PTGBD in patient with acute cholecystitis

Fig. 8 Forest plot of mortality of LC after PTGBD in patient with acute cholecystitis
Study

$\%$

ID

RR $(95 \% \mathrm{Cl}) \quad$ Weight

Time between PTGBD and $L C<7$ days

Kim (2000)

Chikamori (2002)

Kim(1) (2009)

Choi (2012)

$\mathrm{Na}$ (2015)

Jia (2018)

Subtotal (I-squared $=0.0 \%, p=0.839$ )

Time between PTGBD and LC >7 days

Time between PT

Kim (2008)

Kim(2)(2009)

$\mathrm{Hu}$ (2015)

Ni (2015)

El-Gendi (2017)

Jung (2017)

Ke (2018)

Subtotal $(I-$ squared $=0.0 \%, p=0.562)$

Overall (I-squared $=0.0 \%, p=0.767)$

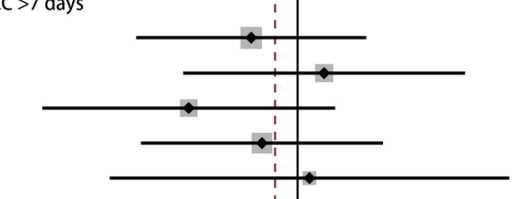

$1.68(0.11,26.00) \quad 5.34$

$0.12(0.01,2.08) \quad 4.95$

$0.50(0.05,5.27) \quad 7.24$

$1.26(0.03,61.42) \quad 2.66$

$0.06(0.00,1.00) \quad 5.00$

$3.88(0.16,94.55) \quad 3.94$

$0.32(0.03,2.97) \quad 8.09$

$0.44(0.17,1.12) \quad 45.25$

$0.65(0.34,1.22) \quad 100.00$

NOTE: Weights are from random effects analysis

Study

ID
$\%$

Weight

Time between PTGBD and $\mathrm{LC}<7$ days

Kim (2000)

Kim (1) (2009)

Kim (2011)

$\mathrm{Na}$ (2015)

Jia (2018)

Subtotal (I-squared $=0.0 \%, p=0.971$ )

Time between PTGBD and LC $>7$ days

Tsumura (2004)

Kim (2008)

Kim(2) (2009)

$\mathrm{Hu}$ (2015)

$\mathrm{Ni}$ (2015)

El-Gendi (2017)

Ke (2018)

Subtotal (I-squared $=0.0 \%, p=0.995)$

Overall (I-squared $=0.0 \%, p=0.999)$

NOTE: Weights are from random effects analysis
RR $(95 \% \mathrm{Cl})$

$1.64(0.03,80.49)$

$1.69(0.03,83.56)$

$0.50(0.02,12.23)$

$0.66(0.07,6.12)$

6.45

6.42

9.59

19.63

$0.42(0.02,10.00) \quad 9.70$

$0.73(0.18,2.86) \quad 51.78$

$121(0.02,60.25) \quad 6.40$

$4.97(0.21,119.03) \quad 9.68$

$1.56(0.03,77.21) \quad 6.42$

$1.00(0.02,49.04) \quad 6.44$

$1.26(0.03,61.42) \quad 6.46$

$1.00(0.02,49.75) \quad 6.39$

$0.96(0.02,47.42) \quad 6.42$

$1.54(0.37,6.40) \quad 48.22$

$1.04(0.39,2.80) \quad 100.00$ 
difference in heterogeneity among the studies $(Q=9.07 ; P$ for heterogeneity $=0.767 ; I^{2}=0 \%$ ).

\section{Mortality}

Eleven studies $[3,4,10,17,28-34]$ reported mortality rates. As shown in Fig. 8, 556 patients underwent LC after PTGBD, and 702 underwent ELC. According to the random-effects model, there were no significant differences in mortality between the two groups (RR 1.04 ; 95\% CI $0.39-2.80 ; P=0.933)$. There was no significant difference in heterogeneity among the studies $(Q=1.78 ; P$ for heterogeneity $\left.=0.999 ; I^{2}=0 \%\right)$.

\section{Publication bias analysis}

In this study, potential publication bias was investigated using Begg's and Egger's tests. The two plots for biliary leakage did not show obvious visual asymmetry (Fig. 9), and the $P$ values of Egger's test were also greater than 0.05

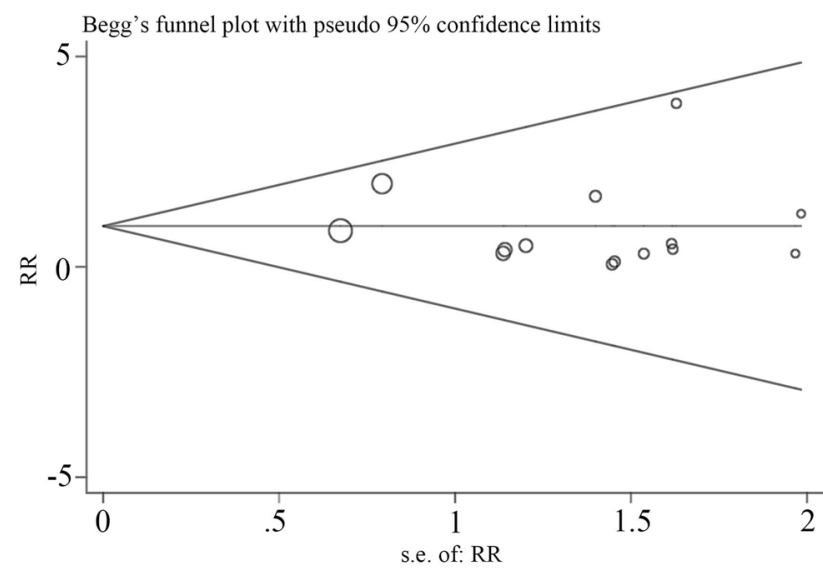

A

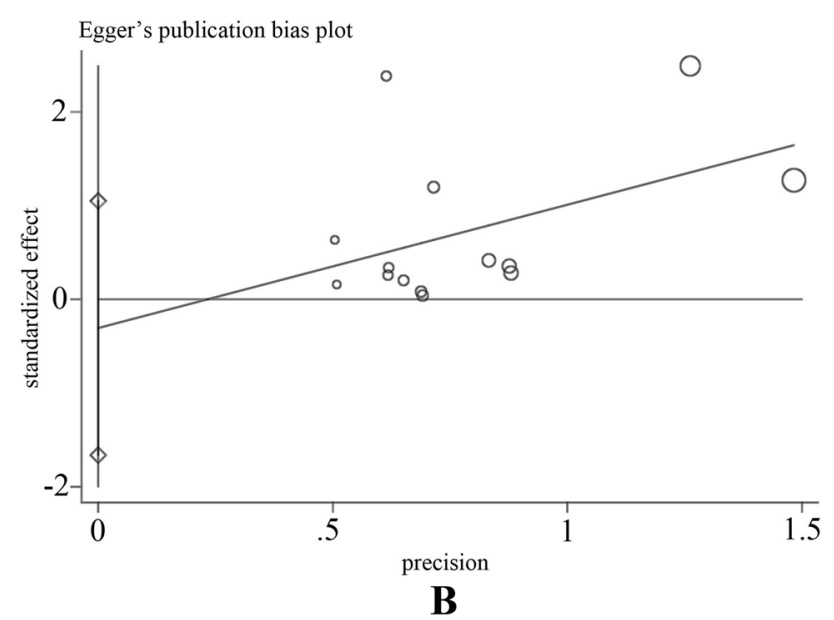

Fig. 9 Begg's funnel plot (a) and Egger's test (b) of biliary leak were used to evaluate the publication bias
$(P=0.632)$. Moreover, the other $P$ values of the index of the test were greater than 0.05 (data not shown). Therefore, there was no significant publication bias in this meta-analysis.

\section{Discussion}

AC patients may present with a wide spectrum of disease severities linked to the operative difficulty, leading to the possibility of bile duct injury when AC patients undergo LC [2-4]. Several studies have also endorsed the usefulness of PTGBD for AC with a high success rate of efficacious drainage and a low complication rate, making it is a suitable treatment for AC patients [29, 30,36]. However, no randomized controlled trials have been performed to clarify the advantages of both approaches. In addition, in clinical practice, many physicians decide their treatment strategies mostly based on local experience and personal preferences owing to the ambiguous indications for PTGBD [3, 34]. This leads to a controversial comparison between ELC and DLC after PTGBD. Given this background, we performed a metaanalysis to further clarify the safety and efficacy of ELC and PTGBD followed by DLC in AC patients.

The pooled analysis of the 15 included retrospective studies provided moderate quality evidence in favor of DLC after PTGBD for the treatment of acute cholecystitis. Our results showed that DLC after PTGBD had the advantages of a short operative time, a low conversion rate and limited intraoperative blood loss. However, there were no significant differences in several aspects including the postoperative length of hospital stay, postoperative complications, biliary leakage and mortality.

According to our analysis, DLC after PTGBD demonstrated a shorter operation duration than ELC (SMD - 0.51; $95 \% \mathrm{CI}-0.89$ to $-0.13 ; P=0.008)$. This finding could be related to the alleviation of local inflammation after PTGBD. As a minimally invasive procedure, PTGBD decompresses gallbladder distention and alleviates edema of the gallbladder wall and pericholecystic inflammation [6]. The clinical symptoms of AC in patients with good preoperative conditions can be immediately relieved by PTGBD [37]. According to a study from $\mathrm{Hu}$ et al. [30], $35 \mathrm{AC}$ patients who underwent successful PTGBD had decompressed gallbladders and normal body temperatures within $72 \mathrm{~h}$. Our result is also consistent with that of Chikamori et al. [16], who found that the duration of LC was shortened when cholecystectomy was performed as soon as possible after PTGBD. In addition, PTGBD can be employed for cholangiography to reveal the biliary tract anatomy and provide clear information about the surgical site, which might facilitate operative procedures [38].

Our analysis of the conversion rate suggested that DLC had a significantly lower potential to cause conversion 
to open surgery than ELC (RR 0.43 ; 95\% CI $0.26-0.69$; $P=0.001$ ). Previous studies concluded that the root cause of conversion was repetitively progressive inflammation with distended and edematous walled gallbladders $[39,40]$. The low conversion rate in the DLC group may be attributed to PTGBD, as PTGBD has the ability to relieve inflamed gallbladder adhesions [15]. On the other hand, emergency laparoscopic cholecystectomy is regarded as a challenging procedure in $\mathrm{AC}$ patients due to the frequent presence of adhesions around the acutely inflamed gallbladder and the high incidence of bile duct injuries [41]. In addition, in clinical practice, due to restrictions involving ethics, there might have been bias in terms of the selection of patients who had undergone PTGBD, as the patients in the DLC group had more severe preoperative inflammation, a higher risk of ASA classification and a poorer general condition than the patients in the ELC group [6, 15, 42]; DLC patients may have had severe inflammation and dense adhesions with an increased risk of conversion to laparotomy [43]. However, our conversion rate results still showed that DLC was superior to ELC, regardless of the effect of PTGBD. Our subgroup analysis also showed that there was no significant difference in the rate of conversion to open surgery when LC was performed within 7 days of or 7 days after PTGBD, similar to the results of previous studies [44, 45].

Our analysis of intraoperative hemorrhage revealed that DLC demonstrated less blood loss than ELC (SMD - 0.59; $95 \%$ CI -0.96 to $-0.22 ; P=0.002)$. PTGBD can immediately relieve the decompression of swollen gallbladders and pericholecystic inflammation to prevent the development of fibrosis in Calot's triangle [37, 46]. With the help of PTGBD, the operation field of Calot's triangle is much clearer, which facilitates laparoscopic cholecystectomy and reduces blood loss during the operation. In addition, surgeons have less information about patients who undergo ELC than what is routinely required. In contrast, during the preoperative period, the surgeon can identify the DLC patient's underlying disease and the status of the biliary system, together with sufficient laboratory and radiological test results and surgical planning, which can enhance the patient's safety [15, 34].

Our analysis of the hospital stay suggested that DLC after PTGBD had a significantly longer time of the total hospital stay than ELC (SMD 0.91; 95\% CI 0.57 to $1.24 ; P<0.001$ ). Because of hospitalization for PTGBD, the time of total hospital stay was much longer in the PTGBD+ DLC group. In clinical practice, patients in the PTGBD + DLC group may have poor general conditions and severe preoperative inflammation, which may need more time to retain the drainage [6, 15, 42]. Lo et al. [47] reported that PTGBD had the adverse outcome of a longer hospital stay for the management of gallbladder perforation, while urgent LC without PTGBD had similar surgical outcomes as that of elective LC with
PTGBD. But previous studies suggested that AC patients treated with ELC may have a shorter postoperative hospital stay and lower hospital costs than those who underwent DLC without PTGBD [48-50].

Our analysis showed that there was no significant difference in terms of complications, biliary leakage or mortality. Apart from the complications caused by LC, PTGBD can also lead to complications related to the procedure. In the 49 patients with PTGBD from Ke's study [17], there were 23 patients had postoperative complications after PTGBD and 12 cases among were associated with the drainage tube, such as bile leakage, hepatapostema and common bile duct stone. The complications caused by PTGBD may be associated with the long-time drainage and the underlying disease. However, patients in the EC group have higher incidence of respiratory failure and admission to the ICU, which contrarily indicates the effect of PTGBD on reducing severe complications after cholecystectomy in AC patients [17]. Besides, Giger et al. [43] analyzed more than 20,000 patients treated with LC and suggested that emergency surgery may be an independent risk factor for possible perioperative complications. In addition, Jackson et al. [51] and Jia et al. [29] suggested that postoperative complications may be associated with operative time and intraoperative blood loss, while our analysis showed a shorter operative time and less intraoperative blood loss in the DLC group than in the ELC group, which may imply a better outcome in terms of postoperative complications.

In our subgroup analysis, we divided studies into two groups based on the time interval between PTGBD and LC. Although it was not significant, probably because of the rough treatment of PTGBD time, the PTGBD time may affect the outcome of AC patients. Choi et al. [15] and Han et al. [52] reported that patients who underwent LC within $72 \mathrm{~h}$ after PTGBD had a worse outcome than those who underwent LC more than $72 \mathrm{~h}$ after PTGBD. These results can be explained by the fact that the short duration of PTGBD may cause the incompleteness of fistula formation around the PTGBD tube, and inflammation is not alleviated well enough for cholecystectomy [16].

Undoubtedly, there are several limitations in this metaanalysis. The quality of the included studies was deemed moderate, and all of the included studies were retrospective in nature, with the dearth of randomized controlled trials performed for ELC and PTGBD + DLC. Furthermore, limited by ethics, there was a bias in the selection of patients treated with PTGBD + DLC, as the patients in the DLC group may have worse conditions for cholecystectomy $[6,15,42]$. And patients who received PTGBD failed to undergo DLC are not reported in the literatures we included, which may lead to a publication bias in our meta-analysis. Finally, most of the included studies were performed in Asia, and the data regarding ELC and DLC in Europe and 
America were unclear. Randomized controlled trials and multicenter studies with a large sample size are needed to verify the outcomes of this meta-analysis.

In conclusion, our meta-analysis suggested that delayed cholecystectomy after PTGBD may be preferred over emergency cholecystectomy, as it had a shorter operative time, a lower conversion rate and less intraoperative blood loss. Therefore, delayed laparoscopic cholecystectomy after percutaneous transhepatic gallbladder drainage might be a good approach for patients with acute cholecystitis.

Author contributions S-ZH, H-QC and W-CL contributed to study design; $\mathrm{S}-\mathrm{ZH}$ and $\mathrm{H}-\mathrm{QC}$ contributed to manuscript writing and study selection; W-XL and HZ contributed to data analysis; W-YZ and J-HC contributed to proofreading; $\mathrm{BL}$ is a senior author and conceptualized the research project; $\mathrm{K}-\mathrm{PH}$ is the corresponding author and supervised the research project.

Funding Funding supported by Grants from the National Natural Science Foundation of China (81702375) and the Training program for young teachers of Sun Yat-sen University (19ykpy32).

\section{Compliance with ethical standards}

Conflict of interest All authors have no conflicts of interest or financial ties to disclose.

Research involving human participants and/or animals This article does not contain any studies with human participants or animals performed by any of the authors.

Informed consent For this type of study, formal consent is not required.

Open Access This article is licensed under a Creative Commons Attribution 4.0 International License, which permits use, sharing, adaptation, distribution and reproduction in any medium or format, as long as you give appropriate credit to the original author(s) and the source, provide a link to the Creative Commons licence, and indicate if changes were made. The images or other third party material in this article are included in the article's Creative Commons licence, unless indicated otherwise in a credit line to the material. If material is not included in the article's Creative Commons licence and your intended use is not permitted by statutory regulation or exceeds the permitted use, you will need to obtain permission directly from the copyright holder. To view a copy of this licence, visit http://creativecommons.org/licenses/by/4.0/.

\section{References}

1. Loozen CS, van Santvoort HC, van Duijvendijk P et al (2018) Laparoscopic cholecystectomy versus percutaneous catheter drainage for acute cholecystitis in high risk patients (chocolate): Multicentre randomised clinical trial. BMJ 363:k3965. https://doi. org/10.1136/bmj.k3965

2. Portincasa P, Moschetta A, Palasciano G (2006) Cholesterol gallstone disease. Lancet 368:230-239. https://doi.org/10.1016/s0140 -6736(06)69044-2
3. El-Gendi A, El-Shafei M, Emara D (2017) Emergency versus delayed cholecystectomy after percutaneous transhepatic gallbladder drainage in grade II acute cholecystitis patients. J Gastrointest Surg 21:284-293. https://doi.org/10.1007/s11605-016-3304-y

4. Na BG, Yoo YS, Mun SP et al (2015) The safety and efficacy of percutaneous transhepatic gallbladder drainage in elderly patients with acute cholecystitis before laparoscopic cholecystectomy. Ann Surg Treat Res 89:68-73. https://doi.org/10.4174/ astr.2015.89.2.68

5. Litynski GS (1998) Erich muhe and the rejection of laparoscopic cholecystectomy (1985): a surgeon ahead of his time. Jsls 2:341-346

6. Jung BH, Park JI (2017) Impact of scheduled laparoscopic cholecystectomy in patients with acute cholecystitis, following percutaneous transhepatic gallbladder drainage. Ann Hepatobiliary Pancreat Surg 21:21-29. https://doi.org/10.14701/ahbps.2017.21.1.21

7. Wakabayashi G, Iwashita Y, Hibi T et al (2018) Tokyo guidelines 2018: surgical management of acute cholecystitis: safe steps in laparoscopic cholecystectomy for acute cholecystitis (with videos). J Hepatobiliary Pancreat Sci 25:73-86. https://doi. org/10.1002/jhbp.517

8. Kortram K, van Ramshorst B, Bollen TL et al (2012) Acute cholecystitis in high risk surgical patients: Percutaneous cholecystostomy versus laparoscopic cholecystectomy (chocolate trial): study protocol for a randomized controlled trial. Trials 13:7. https://doi. org/10.1186/1745-6215-13-7

9. To KB, Cherry-Bukowiec JR, Englesbe MJ et al (2013) Emergent versus elective cholecystectomy: conversion rates and outcomes. Surg Infect (Larchmt) 14:512-519. https://doi.org/10.1089/ sur.2012.160

10. Ni Q, Chen D, Xu R et al (2015) The efficacy of percutaneous transhepatic gallbladder drainage on acute cholecystitis in highrisk elderly patients based on the Tokyo guidelines. Medicine (United States) 94:e1442. https://doi.org/10.1097/MD.00000 00000001442

11. Radder RW (1980) Ultrasonically guided percutaneous catheter drainage for gallbladder empyema. Diagn Imaging 49:330-333

12. Mori Y, Itoi T, Baron TH et al (2018) Tokyo guidelines 2018: management strategies for gallbladder drainage in patients with acute cholecystitis (with videos). J Hepatobiliary Pancreat Sci 25:87-95. https://doi.org/10.1002/jhbp.504

13. Tomizawa M, Shinozaki F, Tanaka S et al (2017) Diffusionweighted whole-body magnetic resonance imaging with background body signal suppression/t 2 image fusion for the diagnosis of acute cholecystitis. Exp Ther Med 14:730-734. https://doi. org/10.3892/etm.2017.4561

14. Melloul E, Denys A, Demartines N et al (2011) Percutaneous drainage versus emergency cholecystectomy for the treatment of acute cholecystitis in critically ill patients: does it matter? World J Surg 35:826-833. https://doi.org/10.1007/s00268-011-0985-y

15. Choi JW, Park SH, Choi SY et al (2012) Comparison of clinical result between early laparoscopic cholecystectomy and delayed laparoscopic cholecystectomy after percutaneous transhepatic gallbladder drainage for patients with complicated acute cholecystitis. Korean J Hepatobiliary Pancreat Surg 16:147-153. https ://doi.org/10.14701/kjhbps.2012.16.4.147

16. Chikamori F, Kuniyoshi N, Shibuya S et al (2002) Early scheduled laparoscopic cholecystectomy following percutaneous transhepatic gallbladder drainage for patients with acute cholecystitis. Surg Endosc 16:1704-1707. https://doi.org/10.1007/s0046 4-002-9004-6

17. Ke CW, Wu SD (2018) Comparison of emergency cholecystectomy with delayed cholecystectomy after percutaneous transhepatic gallbladder drainage in patients with moderate acute cholecystitis. J Laparoendosc Adv Surg Tech A 28:705-712. https:// doi.org/10.1089/lap.2017.0502 
18. Dimou FM, Adhikari D, Mehta HB et al (2017) Outcomes in older patients with grade III cholecystitis and cholecystostomy tube placement: a propensity score analysis. J Am Coll Surg 224:502511.e501. https://doi.org/10.1016/j.jamcollsurg.2016.12.021

19. Bueno Lledo J, Planells Roig M, Arnau Bertomeu C et al (2006) Outpatient laparoscopic cholecystectomy: a new gold standard for cholecystectomy. Rev Esp Enferm Dig 98:14-24. https://doi. org/10.4321/s1130-01082006000100003

20. Liberati A, Altman DG, Tetzlaff J et al (2009) The Prisma statement for reporting systematic reviews and meta-analyses of studies that evaluate healthcare interventions: explanation and elaboration. BMJ 339:b2700. https://doi.org/10.1136/bmj.b2700

21. Hozo SP, Djulbegovic B, Hozo I (2005) Estimating the mean and variance from the median, range, and the size of a sample. BMC Med Res Methodol 5:13. https://doi.org/10.1186/1471-2288-5-13

22. Slim K, Nini E, Forestier D et al (2003) Methodological index for non-randomized studies (minors): development and validation of a new instrument. ANZ J Surg 73:712-716. https://doi.org/10.10 46/j.1445-2197.2003.02748.x

23. DerSimonian R, Laird N (1986) Meta-analysis in clinical trials. Control Clin Trials 7:177-188. https://doi.org/10.1016/01972456(86)90046-2

24. Higgins JP, Thompson SG (2002) Quantifying heterogeneity in a meta-analysis. Stat Med 21:1539-1558. https://doi.org/10.1002/ sim. 1186

25. Higgins JP, Thompson SG, Deeks JJ et al (2003) Measuring inconsistency in meta-analyses. BMJ 327:557-560. https://doi. org/10.1136/bmj.327.7414.557

26. Langhorne P (1998) Bias in meta-analysis detected by a simple, graphical test. Prospectively identified trials could be used for comparison with meta-analyses. BMJ 316:471

27. Begg CB, Mazumdar M (1994) Operating characteristics of a rank correlation test for publication bias. Biometrics 50:1088-1101

28. Kim KH, Sung CK, Park BK et al (2000) Percutaneous gallbladder drainage for delayed laparoscopic cholecystectomy in patients with acute cholecystitis. Am J Surg 179:111-113. https://doi. org/10.1016/s0002-9610(00)00247-6

29. Jia B, Liu K, Tan L et al (2018) Percutaneous transhepatic gallbladder drainage combined with laparoscopic cholecystectomy versus emergency laparoscopic cholecystectomy in acute complicated cholecystitis: comparison of curative efficacy. Am Surg 84:438-442

30. Hu YR, Pan JH, Tong XC et al (2015) Efficacy and safety of b-mode ultrasound-guided percutaneous transhepatic gallbladder drainage combined with laparoscopic cholecystectomy for acute cholecystitis in elderly and high-risk patients. BMC Gastroenterol 15:81. https://doi.org/10.1186/s12876-015-0294-2

31. Tsumura H, Ichikawa T, Hiyama E et al (2004) An evaluation of laparoscopic cholecystectomy after selective percutaneous transhepatic gallbladder drainage for acute cholecystitis. Gastrointest Endosc 59:839-844. https://doi.org/10.1016/s0016 -5107(04)00456-0

32. Kim JH, Kim JW, Jeong IH et al (2008) Surgical outcomes of laparoscopic cholecystectomy for severe acute cholecystitis. J Gastrointest Surg 12:829-835. https://doi.org/10.1007/s1160 5-008-0504-0

33. Kim HO, Ho Son B, Yoo CH et al (2009) Impact of delayed laparoscopic cholecystectomy after percutaneous transhepatic gallbladder drainage for patients with complicated acute cholecystitis. Surg Laparosc Endosc Percutan Tech 19:20-24. https://doi. org/10.1097/SLE.0b013e318188e2fe

34. Kim IG, Kim JS, Jeon JY et al (2011) Percutaneous transhepatic gallbladder drainage changes emergency laparoscopic cholecystectomy to an elective operation in patients with acute cholecystitis. J Laparoendosc Adv Surg Tech A 21:941-946. https://doi. org/10.1089/lap.2011.0217
35. Lee R, Ha H, Han YS et al (2017) Percutaneous transhepatic gallbladder drainage followed by elective laparoscopic cholecystectomy for patients with moderate to severe acute cholecystitis. Medicine (Baltimore) 96:e8533. https://doi.org/10.1097/ md.0000000000008533

36. Xu EJ, Zheng RQ, Su ZZ et al (2012) Intra-biliary contrastenhanced ultrasound for evaluating biliary obstruction during percutaneous transhepatic biliary drainage: a preliminary study. Eur J Radiol 81:3846-3850. https://doi.org/10.1016/j.ejrad.2012.06.025

37. Ihama Y, Fukazawa M, Ninomiya K et al (2012) Peritoneal bleeding due to percutaneous transhepatic gallbladder drainage: an autopsy report. World J Hepatol 4:288-290. https://doi. org/10.4254/wjh.v4.i10.288

38. Fidelman N, Kerlan RK Jr, Laberge JM et al (2011) Accuracy of percutaneous transhepatic cholangiography in predicting the location and nature of major bile duct injuries. J Vasc Interv Radiol 22:884-892. https://doi.org/10.1016/j.jvir.2011.02.007

39. Lo CM, Liu CL, Fan ST et al (1998) Prospective randomized study of early versus delayed laparoscopic cholecystectomy for acute cholecystitis. Ann Surg 227:461-467. https://doi. org/10.1097/00000658-199804000-00001

40. Kolla SB, Aggarwal S, Kumar A et al (2004) Early versus delayed laparoscopic cholecystectomy for acute cholecystitis: a prospective randomized trial. Surg Endosc 18:1323-1327. https://doi. org/10.1007/s00464-003-9230-6

41. Kum CK, Eypasch E, Lefering R et al (1996) Laparoscopic cholecystectomy for acute cholecystitis: is it really safe? World J Surg 20:43-48. https://doi.org/10.1007/s002689900008(discussion 48-49)

42. Chandler CF, Lane JS, Ferguson P et al (2000) Prospective evaluation of early versus delayed laparoscopic cholecystectomy for treatment of acute cholecystitis. Am Surg 66:896-900

43. Giger UF, Michel JM, Opitz I et al (2006) Risk factors for perioperative complications in patients undergoing laparoscopic cholecystectomy: analysis of 22,953 consecutive cases from the Swiss association of laparoscopic and thoracoscopic surgery database. J Am Coll Surg 203:723-728. https://doi.org/10.1016/j.jamcollsur g.2006.07.018

44. Knight JS, Mercer SJ, Somers SS et al (2004) Timing of urgent laparoscopic cholecystectomy does not influence conversion rate. Br J Surg 91:601-604. https://doi.org/10.1002/bjs.4539

45. Tzovaras G, Zacharoulis D, Liakou P et al (2006) Timing of laparoscopic cholecystectomy for acute cholecystitis: a prospective non randomized study. World J Gastroenterol 12:5528-5531. https ://doi.org/10.3748/wjg.v12.i34.5528

46. Tsuyuguchi T, Takada T, Kawarada Y et al (2007) Techniques of biliary drainage for acute cholecystitis: Tokyo guidelines. J Hepatobiliary Pancreat Surg 14:46-51. https://doi.org/10.1007/ s00534-006-1155-8

47. Lo H-C, Wang Y-C, Su L-T et al (2012) Can early laparoscopic cholecystectomy be the optimal management of cholecystitis with gallbladder perforation? A single institute experience of 74 cases. Surg Endosc 26:3301-3306. https://doi.org/10.1007/s0046 4-012-2344-y

48. Daniak CN, Peretz D, Fine JM et al (2008) Factors associated with time to laparoscopic cholecystectomy for acute cholecystitis. World J Gastroenterol 14:1084-1090. https://doi.org/10.3748/ wjg. 14.1084

49. Farooq T, Buchanan G, Manda V et al (2009) Is early laparoscopic cholecystectomy safe after the "safe period"? J Laparoendosc Adv Surg Tech A 19:471-474. https://doi.org/10.1089/lap.2008.0363

50. Pessaux P, Tuech JJ, Rouge C et al (2000) Laparoscopic cholecystectomy in acute cholecystitis. a prospective comparative study in patients with acute vs. chronic cholecystitis. Surg Endosc 14:358361. https://doi.org/10.1007/s004640020088 
51. Jackson TD, Wannares JJ, Lancaster RT et al (2011) Does speed matter? The impact of operative time on outcome in laparoscopic surgery. Surg Endosc 25:2288-2295. https://doi.org/10.1007/ s00464-010-1550-8

52. Han IW, Jang JY, Kang MJ et al (2012) Early versus delayed laparoscopic cholecystectomy after percutaneous transhepatic gallbladder drainage. J Hepatobiliary Pancreat Sci 19:187-193. https://doi.org/10.1007/s00534-011-0458-6
Publisher's Note Springer Nature remains neutral with regard to jurisdictional claims in published maps and institutional affiliations. 